\title{
Estimated glomerular filtration rate by serum cystatin $C$ correlates with cardiometabolic parameters in patients with primary hyperparathyroidism
}

\author{
Federica Ermetici, Marcello Filopanti ${ }^{1}$, Uberta Verga ${ }^{1}$, Elena Passeri ${ }^{2}$, Giorgia Dito ${ }^{2}$, \\ Alexis Elias Malavazos, Chiara Mapelli ${ }^{3}$, Maria Elisabetta Raggi ${ }^{3}$, Anna Spada ${ }^{4}$ \\ and Sabrina Corbetta ${ }^{5}$
}

\begin{abstract}
Diabetology and Metabolic Disease Unit, IRCCS Policlinico San Donato, San Donato Milanese, Milan, Italy, ${ }^{1}$ Endocrine and Diabetology Unit, Fondazione IRCCS Ca' Granda Ospedale Maggiore Policlinico, Milan, Milan, Italy, ${ }^{2}$ Endocrinology Unit, IRCCS Policlinico San Donato, San Donato Milanese, Milan, Italy,

${ }^{3}$ Clinical Pathology Laboratory, IRCCS E. Medea, Bosisio Parini, Lecco, Italy, ${ }^{4}$ Endocrine and Diabetology Unit, Department of Clinical Sciences and Community Health, University of Milan, Fondazione IRCCS Cà Granda Ospedale Maggiore Policlinico, Milan, Milan, Italy and ${ }^{5}$ Endocrinology Unit, Department of Biomedical Sciences for Health, University of Milan, IRCCS Policlinico San Donato, Via Morandi 30, 20097 San Donato Milanese, Milan, Italy
\end{abstract}

\author{
Correspondence \\ should be addressed \\ to S Corbetta \\ Email \\ sabrina.corbetta@unimi.it
}

\begin{abstract}
Objective: Patients with primary hyperparathyroidism (PHPT) are at risk of chronic kidney disease (CKD). Cystatin C (Cys-C) is considered a more reliable tool to assess glomerular filtration rate (GFR) than creatinine. The study aimed to assess circulating Cys- $\mathrm{C}$ and its relationships with biochemical PHPT and cardiometabolic parameters.

Design and methods: The present cross-sectional study was performed in academic endocrine units on PHPT patients $(n=190)$ and non-hypertensive, non-diabetic, age- and sex-matched healthy controls $(n=135)$ with no established CKD. The main outcomes were creatinine by alkaline picrate method, Cys-C by immunonephelometry and calculation of estimated GFR based on creatinine and Cys-C (eGFRcr-cys) using the CKD-EPI equation.

Results: In PHPT patients, circulating Cys-C ranged $0.45-3.13 \mathrm{mg} / \mathrm{l}$ and correlated with creatinine, age and BMI. Mean Cys-C level was higher in PHPT patients than in controls $(0.93 \pm 0.02$ vs $0.78 \pm 0.14 \mathrm{mg} / \mathrm{l} ; P=0.03)$. Cys-C levels in PHPT patients were predicted by age, BMI, ionized calcium, hypertension and HDL-cholesterol, the most significant determinant being ionized calcium. Cys-C positively correlated with cardiovascular disease (CVD) occurrence. Overall, $18.4 \%$ of PHPT patients with eGFRcr $>60 \mathrm{ml} / \mathrm{min}$ per $1.73 \mathrm{~m}^{2}(n=169)$ had Cys-C levels higher than the 95th percentile in controls $(1.03 \mathrm{mg} / \mathrm{l})$, consistent with a preclinical CKD, which was associated with hypertension and insulin resistance. Considering eGFRcr-cys, CKD (stages G3a, G3b, 4) was diagnosed in 13.7\% of PHPT patients. Estimated GFRcr-cys, but not eGFR based on creatinine, was predicted by insulin resistance and hypertension and positively correlated with CVD.

Conclusions: Elevated Cys-C levels were associated with ionized calcium, cardiometabolic risk factors and CVD, and identified preclinical CKD in PHPT patients.

\section{Introduction}

Primary hyperparathyroidism (PHPT) is the third most common endocrine disorder. Kidney is a target of PTH action: a subset of PHPT patients ranging from 7 to $35 \%$ experienced kidney stones or, less frequently, nephrocalcinosis $(1,2)$. Reduction of glomerular filtration rate (GFR, $<60 \mathrm{ml} / \mathrm{min}$ ) has been reported in both symptomatic,
(C) 2015 European Society of Endocrinology Printed in Great Britain
Published by Bioscientifica Ltd 
affected with kidney stones and osteoporosis, and asymptomatic PHPT patients $(3,4,5)$, and is considered a criteria for surgery in patients with asymptomatic PHPT according the clinical guidelines from the Fourth International Workshop (6).

The Chronic Kidney Disease Epidemiology Collaboration (CKD-EPI) equation is recommended for reporting estimated GFR (eGFR) from serum creatinine levels in adults (7). Cystatin C (Cys-C), a low-molecular weight protein secreted by nearly all cells, freely filtered at renal glomerular level and then metabolized by the proximal tubule, is considered a more reliable tool to assess GFR than serum creatinine as it is not affected by factors like sex, race and muscle mass. Indeed, Cys- $\mathrm{C}$ shows a higher correlation with standard measures of GFR when compared with creatinine (8). Moreover, Cys-C levels have been demonstrated to display stronger associations with adverse outcomes related to impaired kidney function, such as cardiovascular disease (CVD), heart failure and all-cause mortality in different populations, than eGFR derived from creatinine $(9,10)$.

In the present study, we evaluated i) serum Cys-C levels and its correlation with clinical, biochemical and cardiometabolic parameters, ii) kidney function by the eGFR equation based on both cystatin and creatinine levels (eGFRcr-cys), and iii) association of eGFRcr-cys with the occurrence of cardiovascular events in a series of PHPT patients.

\section{Subjects and methods}

\section{Subjects}

One-hundred-ninety consecutive patients with PHPT (146 females, 44 males, age $59.7 \pm 14.2$ years) were enrolled in two Italian third-level academic centres (Fondazione IRCCS Ca' Granda, Milan, and IRCCS Policlinico San Donato, San Donato Milanese) from 2005 through 2010. PHPT was diagnosed when hypercalcemia (serum calcium $>10.2 \mathrm{mg} / \mathrm{dl}$ and/or ionized calcium $>1.30 \mathrm{mmol} / \mathrm{l}$ ) and elevated or inappropriately normal PTH level occurred. PHPT was surgically confirmed in 54\% of patients. Exclusion criteria were diagnosis of familial hypocalciuric hypercalcemia (detection of calcium-to-creatinine clearance ratio $>0.01$ following vitamin $\mathrm{D}$ deficiency correction (11)), previously established diagnosis of CKD, hyperthyroidism, pregnancy, glucocorticoids, bisphosphonates, diuretics and calcimimetic treatments. One-hundredthirty-five age- and sex-matched healthy subjects (88 females, 47 males, age $56.0 \pm 17.2$ years) were enrolled as controls; hypertension, diabetes, neoplasia and established CKD were criteria of exclusion. All patients and controls were white Caucasians. Patients underwent clinical and laboratory evaluation, including: i) personal and family medical history; ii) physical examination including arterial blood pressure, weight and height measurement; iii) fasting biochemical evaluation including total and ionized calcium, phosphate, intact PTH, 25hydroxyvitaminD3 (25OHD), glucose, insulin, triglycerides, total and HDL cholesterol as well as creatinine. A $24 \mathrm{~h}$ urine collection was obtained from all patients for urinary calcium and phosphate excretion. The eGFRcr was derived from serum creatinine by the CKD-EPI Creatinine equation (2009), while the eGFRcr-cys was derived by the CKD-EPI Creatinine-Cystatin C equation (2012) using the GFR calculators at http://mdrd.com. Insulin resistance was estimated by using fasting glucose and insulin concentrations with the homeostasis model assessment of insulin resistance (HOMA-IR); iv) imaging evaluation including lumbar and femoral dual-energy X-ray absorptiometry (DXA), vertebral spine X-ray and ultrasound kidney examination. Osteoporosis was diagnosed in 58\% and kidney stones in 54\% of PHPT patients. Moreover, arterial blood hypertension occurred in 51\%, overt type 2 diabetes (T2DM) in $12 \%$, obesity in $13 \%$ and dyslipidemia in $70 \%$ of PHPT patients. The prevalence of osteoporosis, hypertension, T2DM, dyslipidemia and obesity were similar in surgically treated and not-surgically treated PHPT patients, while kidney stones were more prevalent in surgically treated PHPT patients (67\% vs 38\%; $P<0.001)$.

Biochemical and hormonal parameters were assayed by routine methods. Serum creatinine was analyzed by the Jaffe's alkaline picrate method. Serum Cys-C was measured by means of a particle-enhanced immunonephelometric assay (N Latex Cystatin C, Dade Behring, Deerfield, IL, USA) with a nephelometer (BNII, Dade Behring). The sensitivity and specificity of the Cys-C assay were $94 \%$ (95\% CI: 91-96) and 82\% (95\% CI: 76-89) respectively. The inter-assay and intra-assay coefficients of variation were 2.6 and $2.9 \%$ respectively.

All participants gave their informed consent after full explanation of the purpose and nature of all used procedures. The protocol study was approved by the local ethical committee.

\section{Statistical analysis}

Data are expressed as mean \pm s.e. Comparisons between groups were done using the Student's $t$-test, or nonparametric tests if the variables were not normally 
distributed. Pearson or Spearman correlations were used for parametric and non-parametric variables, respectively, as appropriate. The Bonferroni's correction was used for the multiple regression analysis. Predictors of Cys-C and eGFRcys-cr levels were identified by step-wise regression analysis. A $P$ value below 0.05 was considered significant. Statistical analysis was performed using SPSS 18.0 statistical package.

\section{Results}

\section{Serum cystatin C levels in PHPT patients}

Circulating Cys-C concentrations ranged 0.45-3.13 mg/l in PHPT patients and $0.52-2.98 \mathrm{mg} / \mathrm{l}$ in age- and sexmatched controls, with no difference between males and females. Serum Cys-C correlated with serum creatinine in PHPT patients $(r=0.594, P=0.0001$; Fig. 1a) and in controls $(r=0.209, P=0.01)$. In PHPT patients, Cys-C levels positively correlated with age $(r=0.542$, $P=0.0001)$ and BMI $(r=0.270, P=0.0002)$. Median Cys-C level was significantly higher in PHPT patients than in controls $(0.93 \pm 0.02$ vs $0.78 \pm 0.01 \mathrm{mg} / \mathrm{l}, \quad P=0.001$; Fig. 1b), even considering normotensive and normoglycemic PHPT patients $(0.82 \pm 0.19 \mathrm{mg} / \mathrm{l}, P=0.03)$. In particular, $25.8 \%$ of PHPT patients had Cys-C levels higher than the 95th percentile value in controls $(1.03 \mathrm{mg} / \mathrm{l})$. Estimating GFR based on serum creatinine, CKD, defined as eGFRcr $<60 \mathrm{ml} / \mathrm{min}$ per $1.73 \mathrm{~m}^{2}$, was diagnosed in $10.8 \%$ of the PHPT patients. Among PHPT patients with eGFRcr $>60 \mathrm{ml} / \mathrm{min}$ per $1.73 \mathrm{~m}^{2}(n=169), 18.4 \%$ had Cys-C levels $>1.03 \mathrm{mg} / \mathrm{l}$, consistent with a condition of 'preclinical kidney disease' (12). Arterial blood hypertension was more frequent ( $80 \%$ vs $41 \%, P=0.01$ ) and HOMA-IR was higher (4.5 vs $2.1, P=0.008)$ in PHPT patients with preclinical kidney disease compared with patients with conserved kidney function.

Cys-C levels positively correlated with serum total and ionized calcium $(r=0.151, P=0.024$ and $r=0.259$, $P=0.004$ respectively) (Fig. 1c), serum PTH $(r=0.176$, $P=0.01$ ), and negatively with urine calcium and phosphate excretions $(r=-0.349, P=0.0001$ and $r=-0.208$, $P=0.009$ respectively).

Cys-C levels positively correlated with the occurrence of hypertension $(r=0.425, P=0.001)$ and T2DM $(r=0.138$, $P=0.045)$, fasting glycemia $(r=0.133, P=0.046)$, serum insulin $(r=0.295, P=0.0007)$, HOMA-IR $(r=0.315$, $P=0.0004)$, HDL-cholesterol $(r=-0.167, P=0.017)$ and triglycerides levels $(r=0.235, P=0.001)$ in PHPT patients. A multiple stepwise linear regression analysis including
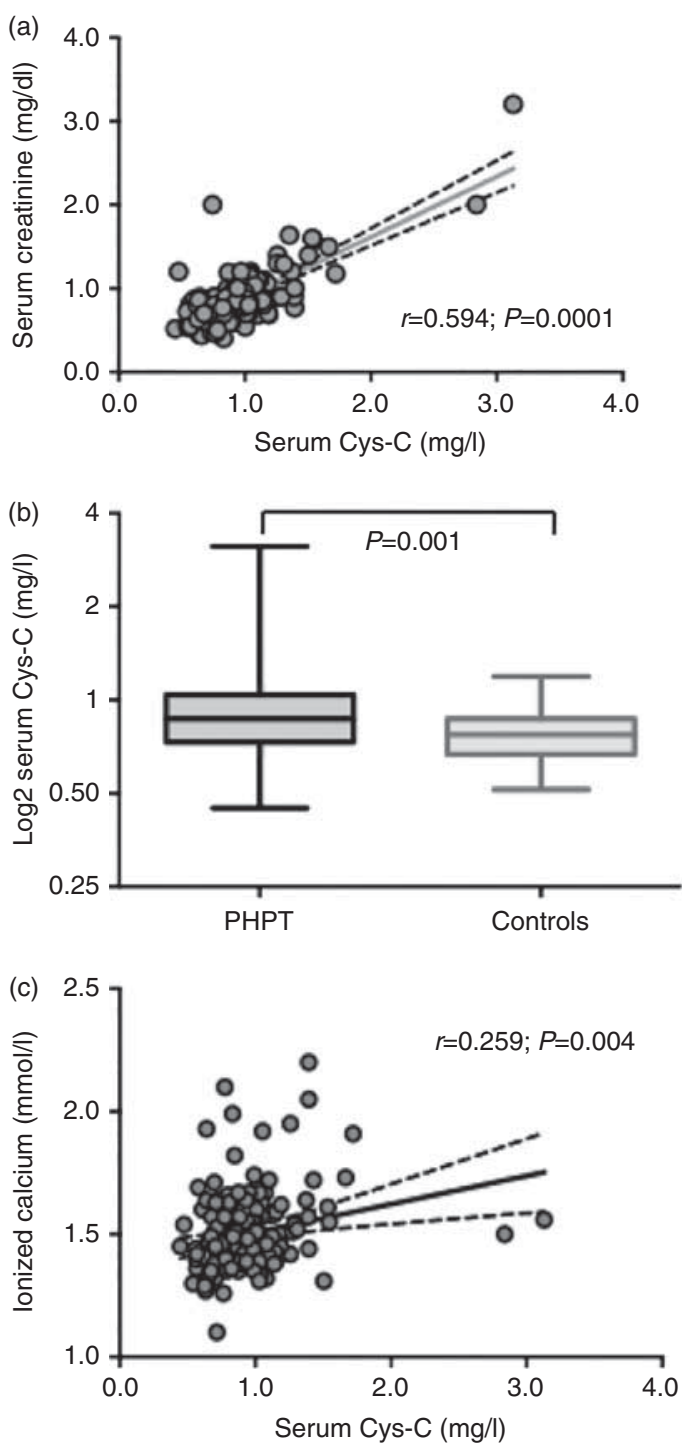

Figure 1

Correlations of serum Cyst-C levels with biochemical parameters defining kidney function and PHPT. In particular, (a) serum Cyst-C levels positively correlated with serum creatinine levels in PHPT patients; dashed lines represent 5 and $95 \%$ confidence bands; (b) mean serum Cyst-C levels in PHPT patients was significantly higher than mean levels in healthy controls; whiskers represent minimum and maximum values; (c) in PHPT patients, ionized calcium levels were positively correlated with serum Cyst-C levels; dashed lines represent 5 and $95 \%$ confidence bands.

serum Cys- $\mathrm{C}$ as the dependent variable and age, BMI, ionized calcium, PTH, hypertension, insulin, HDLcholesterol and triglycerides as independent variables, showed that age, BMI, ionized calcium, hypertension and 
HDL-cholesterol independently predicted Cys-C levels $(\beta \quad 0.005 \pm 0.002,0.012 \pm 0.005,0.450 \pm 0.119,0.010 \pm$ 0.046 and $-0.003 \pm 0.001$ respectively), the most significant determinant being ionized calcium.

\section{Evaluation of kidney function using the eGFRcr-cys equation in PHPT patients}

The eGFRcr-cys equation proposed by CKD-EPI (13) was used to evaluate kidney function in the present cohort of PHPT patients: eGFRcr-cys $\geq 90 \mathrm{ml} / \mathrm{min}$ per $1.73 \mathrm{~m}^{2}$ (stage G1) were detected in $46.9 \%$ of PHPT patients; $39.4 \%$ had eGFRcr-cys $60-89 \mathrm{ml} / \mathrm{min}$ per $1.73 \mathrm{~m}^{2}$ (G2); $10.9 \%$ had eGFRcr-cys $45-59 \mathrm{ml} / \mathrm{min}$ per $1.73 \mathrm{~m}^{2}$ (G3a); $1.7 \%$ had eGFRcr-cys $30-44 \mathrm{ml} / \mathrm{min}$ per $1.73 \mathrm{~m}^{2}$ (G3b); 1.1\% had eGFRcr-cys $15-29 \mathrm{ml} / \mathrm{min}$ per $1.73 \mathrm{~m}^{2}$ (G4) and none had eGFRcr-cys values $<15 \mathrm{ml} / \mathrm{min}$ per $1.73 \mathrm{~m}^{2}$ (G5) (14). Therefore, CKD (stages G3a, 3b and 4) was diagnosed in $13.7 \%$ of PHPT patients. PHPT patients with eGFRcr-cys $<60 \mathrm{ml} / \mathrm{min}$ per $1.73 \mathrm{~m}^{2}$ compared with PHPT patients with eGFRcr-cys $>60 \mathrm{ml} / \mathrm{min}$ per $1.73 \mathrm{~m}^{2}$ had higher serum total and ionized calcium, lower urine calcium excretion and higher PTH levels as expected, while the 25OHD status was similar in the two groups (Table 1). Moreover, PHPT patients with eGFRcr-cys $<60 \mathrm{ml} / \mathrm{min}$ per $1.73 \mathrm{~m}^{2}$ were older, more frequently males, heavier, more insulin-resistant and were more frequently affected with hypertension and kidney cysts (Table 1). Any correlation with the occurrence of kidney stones could be detected. The stepwise regression analysis identified hypertension and HOMA-IR values as independent variables predicting eGFRcr-cys in PHPT patients ( $\beta 0.218 \pm 0.077, P=0.0001$ and $0.126 \pm 0.119, P=0.04$ respectively), while hypertension alone was associated with eGFRcr $(\beta 0.206 \pm 0.09, P=0.0001)$.

\section{Serum cystatin C levels were associated with cardiovascular diseases in PHPT patients}

In the present cohort of PHPT patients, 52 CVD diagnosis (coronaropathy, arrhythmia, cerebral vascular diseases) were recorded at the time of evaluation based on clinical history data collection. After adjustment for age and sex, CVD was positively correlated with Cyst-C levels ( $\beta$ 0.305 $\pm 0.109 ; P=0.006)$ and negatively with eGFRcrcys values $(\beta-0.005 \pm 0.002 ; P=0.011)$, while any correlation could be detected with eGFRcr values. These correlations were significant also including dyslipidemia as independent variable in the regress analysis.
Table 1 Comparison between PHPT patients with CKD (eGFRcr-cys $<60 \mathrm{ml} / \mathrm{min}$ per $1.73 \mathrm{~m}^{2}$ ) and patients with conserved kidney function (eGFRcr-cys $>60 \mathrm{ml} / \mathrm{min}$ per $1.73 \mathrm{~m}^{2}$ ).

\begin{tabular}{|c|c|c|c|}
\hline & \multicolumn{2}{|c|}{$\begin{array}{l}\text { PHPT patients with } \\
\text { eGFRcr-cys }\end{array}$} & \multirow[b]{2}{*}{$\boldsymbol{P}$} \\
\hline & $\begin{array}{l}<60 \mathrm{ml} / \mathrm{min} \\
\text { per } 1.73 \mathrm{~m}^{2}\end{array}$ & $\begin{array}{l}>60 \mathrm{ml} / \mathrm{min} \\
\text { per } 1.73 \mathrm{~m}^{2}\end{array}$ & \\
\hline$n$ & 25 & 161 & \\
\hline Age (years) & $70.0 \pm 1.9$ & $58.8 \pm 1.1$ & 0.0002 \\
\hline $\begin{array}{l}\text { Sex (males/females) } \\
\text { (\% males) }\end{array}$ & $10 / 15(40)$ & $32 / 129(20)$ & 0.047 \\
\hline BMI $\left(\mathrm{kg} / \mathrm{m}^{2}\right)$ & $27.3 \pm 0.9$ & $25.3 \pm 0.4$ & 0.041 \\
\hline Ionized calcium (mmol/l) & $1.59 \pm 0.04$ & $1.48 \pm 0.01$ & 0.003 \\
\hline Serum calcium (mg/dl) & $11.6 \pm 0.23$ & $11.0 \pm 0.07$ & 0.005 \\
\hline Serum phosphate $(\mathrm{mg} / \mathrm{dl})$ & $2.5 \pm 0.10$ & $2.4 \pm 0.04$ & 0.778 \\
\hline Serum PTH (pg/ml) & $300.3 \pm 46.5$ & $166.0 \pm 10.7$ & 0.0001 \\
\hline $\begin{array}{l}\text { Calcium excretion } \\
\text { (mg/kg per } 24 \mathrm{~h})\end{array}$ & $3.4 \pm 0.4$ & $4.8 \pm 0.2$ & 0.019 \\
\hline Phosphate excretion (g/24 h) & $0.72 \pm 0.05$ & $0.75 \pm 0.04$ & 0.690 \\
\hline Serum 25OHD (ng/ml) & $22.3 \pm 4.9$ & $20.3 \pm 1.7$ & 0.690 \\
\hline Blood glucose (mg/dl) & $96.2 \pm 4.5$ & $90.8 \pm 1.3$ & 0.186 \\
\hline Serum insulin (mU/l) & $15.6 \pm 3.3$ & $9.4 \pm 0.7$ & 0.010 \\
\hline HOMA-IR & $4.1 \pm 1.0$ & $2.2 \pm 0.2$ & 0.003 \\
\hline Total-cholesterol (mg/dl) & $203.9 \pm 7.6$ & $209.4 \pm 3.4$ & 0.564 \\
\hline HDL-cholesterol (mg/dl) & $51.7 \pm 4.2$ & $60.4 \pm 1.4$ & 0.044 \\
\hline LDL-cholesterol (mg/dl) & $129.3 \pm 8.9$ & $127.7 \pm 2.9$ & 0.853 \\
\hline Triglycerides (mg/dl) & $139.0 \pm 12.9$ & $127.7 \pm 5.0$ & 0.061 \\
\hline Diabetes (\%) & 12.0 & 11.2 & 0.819 \\
\hline Hypertension (\%) & 84.0 & 47.5 & 0.001 \\
\hline Kidney stones (\%) & 48.0 & 53.0 & 0.764 \\
\hline Kidney cysts (\%) & 65.0 & 28.1 & 0.033 \\
\hline
\end{tabular}

CKD, chronic kidney disease; eGFRcr-cys, estimated glomerular filtration rate based using algorithm considering serum creatinine and cystatin $C$ levels; 25OHD, 25hydroxyvitaminD3; HOMA-IR, homeostasis model assessment-insulin resistance.

\section{Discussion}

In the present study, we first evaluated circulating Cys-C levels in a cohort of PHPT patients without established CKD. Cys-C has been demonstrated a reliable marker of renal function and a good marker of adverse prognosis in the general population (9). In particular, Cys-C showed a higher sensitivity than creatinine in detecting renal function impairment in non-established CKD condition.

PHPT has been recognized as a risk factor for impaired renal function, though the specific relationship between PHPT and this condition is not completely understood. Recent studies demonstrated that prolonged activation of the intrarenal inflammosome is responsible for the loss of kidney function in oxalate crystal nephropathy (15), which frequently occurs in PHPT $(16,17)$.

Assessment of serum Cys-C levels in the present PHPT series showed a good correlation with serum creatinine and eGFRcr. In PHPT patients, the most evident determinant of circulating Cys-C levels was ionized calcium, 
suggesting that severity of PHPT might contribute to kidney function impairment. Though in the general population, kidney stone history has been associated with an increased risk of CKD among women (18), no difference could be detected in Cys-C levels between PHPT stone-formers and non-stone-formers.

Comparison with age- and sex-matched healthy controls identified a quarter of PHPT patients with Cys-C levels higher than the threshold of $1.03 \mathrm{mg} / \mathrm{l}$, the upper limit of the normal range. Similar Cys- $C$ thresholds have been proposed as a mortality discriminator in the overall population (19) and as a marker for the diagnosis of a condition of 'preclinical kidney disease' in patients with eGFRcr $>60 \mathrm{ml} / \mathrm{min}$ per $1.73 \mathrm{~m}^{2}$ (13). In the present PHPT series, preclinical kidney disease occurred in about onesixth of patients, which showed an unfavourable cardiometabolic profile, characterized by higher BMI, insulin resistance, arterial blood hypertension and dyslipidemia. In the general population $(10,12)$, the preclinical or mild kidney disease was associated with increased risk for development of established CKD and for mortality, cardiovascular (CVD) and non-CVD outcomes.

The combination of creatinine and Cys-C (eGFRcrcys) has been suggested to provide more precise GFR estimates than creatinine alone (20), even in elderly individuals (21). Using the eGFRcr-cys equation to estimate GFR in the present PHPT series, CKD was diagnosed in $13.7 \%$ of patients, which is higher than that diagnosed by the eGFR based on creatinine alone $(10.8 \%)$. This value is almost double the $7.1 \%$ prevalence reported by the NHANES 1999-2002 survey on adult participants evaluated by eGFRcr-cys (22) and the $7.0 \%$ reported prevalence in the 2008-2012 National Health Examination Survey in the general Italian population evaluated by eGFRcr (23), confirming that CKD is more frequent in PHPT. Hypertension and insulin resistance/ overt diabetes were the two major clinical conditions associated with reduced eGFRcr-cys in PHPT patients as reported in the general population (14). Moreover, considering major CVD outcomes such as the occurrence of coronaropathy, arrhythmia and cerebrovascular disease, low eGFRcr-cys was associated with CVD diagnosis in PHPT patients, confirming the relationship between impairment of kidney function and cardiovascular risk even in PHPT patients. Estimated-GFRcr failed in detecting the associations between insulin-resistance as well as CVD and kidney function in PHPT patients, suggesting that Cys-C might be more sensitive than creatinine in identifying the relationship between kidney function and the cardiometabolic risk in PHPT.
Admittedly, the present study has some limits: i) it was a cross-sectional study, therefore any conclusion about Cys-C ability to predict kidney function in PHPT can be drawn; ii) comparison with direct GFR measurements was not available; and iii) longitudinal data were lacking. Further studies are mandatory to explore the impact of PHPT on kidney function impairment and progression toward CKD. Cys-C might represent a more sensitive tool than creatinine in defining these items.

\section{Declaration of interest}

The authors declare that there is no conflict of interest that could be perceived as prejudicing the impartiality of the research reported.

\section{Funding}

This work was partially sustained by IRCCS Policlinico San Donato Ricerca Corrente Fund.

\section{Author contribution statement}

F Ermetici, M Filopanti, U Verga, E Passeri and S Corbetta enrolled and evaluated patients and controls. F Ermetici, A E Malavazos and G Dito collected and analysed data; C Mapelli and M E Raggi performed the cystatin C assay. A Spada, F Ermetici and S Corbetta established the study protocol, coordinated the study, wrote and critically revised the manuscript.

\section{References}

1 Rejmark L, Vestergaard P \& Mosekilde L. Nephrolithiasis and renal calcifications in primary hyperparathyroidism. Journal of Clinical Endocrinology and Metabolism 201196 2377-2385. (doi:10.1210/ jc.2011-0569)

2 Cipriani C, Biamonte F, Costa AG, Zhang C, Biondi P, Diacinti D, Pepe J, Piemonte S, Scilitani A, Minisola S et al. Prevalence of kidney stones and vertebral fractures in primary hyperparathyroidism using imaging technology. Journal of Clinical Endocrinology and Metabolism 2015100 1309-1315. (doi:10.1210/jc.2014-3708)

3 Tassone F, Gianotti L, Emmolo I, Ghio M \& Borretta G. Glomerular filtration rate and parathyroid hormone secretion in primary hyperparathyroidism. Journal of Clinical Endocrinology and Metabolism 200994 4458-4461. (doi:10.1210/jc.2009-0587)

4 Yuoo N, Donnan PT, Flynn RW, Murphy MJ, Smith D, Rudman A \& Leese GP. Increased mortality and morbidity in mild primary hyperparathyroid patients. The Parathyroid Epidemiology and Audit Research Study (PEARS). Clinical Endocrinology 201073 30-34.

5 Walker MD, Nickolas T, Kepley A, Lee JA, Zhang C, McMahon DJ \& Silverberg SJ. Predictors of renal function in primary hyperparathyroidism. Journal of Clinical Endocrinology and Metabolism 201499 1885-1892. (doi:10.1210/jc.2013-4192)

6 Bilezikian JP, Brandi ML, Eastell R, Silverberg SJ, Udelsman R, Marcocci C \& Potts JT Jr. Guidelines for the management of asymptomatic primary hyperparathyroidism: summary statement from the Fourth International Workshop. Journal of Clinical Endocrinology and Metabolism 201499 3561-3569. (doi:10.1210/jc.2014-1413)

7 Levey AS, Coresh J, Balk E, Kausz AT, Levin A, Steffes MW, Hogg RJ, Perrone RD, Lau J, Eknoyan G et al. National Kidney Foundation 
practice guidelines for chronic kidney disease: evaluation, classification, and stratification. Annals of Internal Medicine 2003139 137-147. (doi:10.7326/0003-4819-139-2-200307150-00013)

8 Levey AS, Coresh J, Greene T, Stevens LA, Zhang YL, Hendriksen S, Kusek JW, Van Lente F \& Chronic Kidney Disease Epidemiology Collaboration . Using standardized serum creatinine values in the Modification of Diet in Renal Disease Study equation for estimating glomerular filtration rate. Annals of Internal Medicine 2006145 247-254. (doi:10.7326/0003-4819-145-4-200608150-00004)

9 Shlipak MG, Sarnak MJ, Katz R, Fried LF, Seliger SL, Newman AB, Siscovick DS \& Stehman-Breen C. Cystatin C and the risk of death and cardiovascular events among elderly persons. New England Journal of Medicine 2005352 2049-2060. (doi:10.1056/NEJMoa043161)

10 Madero M \& Sarnak M. Association of cystatin C with adverse outcomes. Current Opinion in Nephrology and Hypertension 200918 258-263. (doi:10.1097/MNH.0b013e328326f3dd)

11 Marcocci C, Brandi ML, Scillitani A, Corbetta S, Faggiano A, Gianotti L, Migliaccio S \& Minisola S. Italian Society of Endocrinology Consensus Statement: definition, evaluation and management of patients with mild primary hyperparathyroidism. Journal of Endocrinological Investigation 2015. In press. (doi:10.1007/s40618-015-0261-3)

12 Shlipak MG, Katz R, Sarnak MJ, Fried LF, Newman AB, StehmanBreen C, Seliger SL, Kestenbaum B, Psaty B, Tracy RP et al. Cystatin C and prognosis for cardiovascular and kidney outcomes in elderly persons without kidney disease. Annals of Internal Medicine $2006 \mathbf{1 4 5}$ 237-246. (doi:10.7326/0003-4819-145-4-200608150-00003)

13 Fan L, Inker LA, Rossert J, Froissart M, Rossing P, Mauer M \& Levey AS. Glomerular filtration rate estimation using cystatin $\mathrm{C}$ alone or combined with creatinine as a confirmatory test. Nephrology, Dialysis, Transplantation 201429 1195-1203. (doi:10.1093/ndt/gft509)

14 Levey AS, de Jong PE, Coresh J, El Nahas M, Astor BC, Matsushita K, Gansevoort RT, Kasiske BL \& Eckardt KU. The definition, classification and prognosis of chronic kidney disease: a KDIGO Controversies Conference report. Kidney International 201180 17-28. (doi:10.1038/ki. 2010.483)

15 Kurts C. A crystal-clear mechanism of chronic kidney disease. Kidney International 201384 859-861. (doi:10.1038/ki.2013.251)
16 Corbetta S, Baccarelli A, Aroldi A, Vicentini L, Fogazzi GB, EllerVainicher C, Ponticelli C, Beck-Peccoz P \& Spada A. Risk factors associated to kidney stones in primary hyerparathyrodism. Journal of Endocrinological Investigation 200528 122-128. (doi:10.1007/ BF03345354)

17 Corbetta S, Eller-Vainicher C, Frigerio M, Valaperta R, Costa E, Vicentini L, Baccarelli A, Beck-Peccoz P \& Spada A. Analysis of the 206M polymorphic variant of the SCL26A6 gene encoding a $\mathrm{Cl}^{-}$oxalate transporter in patients with primary hyperparathyroidism. European Journal of Endocrinology/European Federation of Endocrine Societies 2009 160 283-288. (doi:10.1530/EJE-08-0623)

18 Shoag J, Halpern J, Goldfarb DS \& Eisner BH. Risk of chronic and end stage kidney disease in patients with nephrolithiasis. Journal of Urology 2014192 1440-1445. (doi:10.1016/j.juro.2014.05.117)

19 Foley RN, Wang C \& Collins AJ. Cystatin C, mortality risk and clinical triage in US adults: threshold values and hierarchical importance. Nephrology, Dialysis, Transplantation 201126 1831-1837. (doi:10.1093/ ndt/gfq629)

20 Inker LA, Schmid CH, Tighiouart H, Eckfeldt JH, Feldman HI, Greene T, Kusek JW, Manzi J, Van Lente F, Zhang YL et al. Estimating glomerular filtration rate from serum creatinine and cystatin C. New England Journal of Medicine 2012367 20-29. (doi:10.1056/NEJMoa1114248)

21 Fan L, Levey AS, Gudnason V, Eiriksdottir G, Andresdottir MB, Gudmundsdottir H, Indridason OS, Palsson R, Mitchell G \& Inker LA. Comparing GFR estimating equations using cystatin $\mathrm{C}$ and creatinine in elderly individuals. Journal of the American Society of Nephrology 2015. In press. (doi:10.1681/ASN.2014060607)

22 Grams ME, Juraschek SP, Selvin E, Foster MC, Inker LA, Eckfeldt JH, Lev AS \& Coresh J. Trends on the prevalence of reduced GFR in the United States: a comparison of creatinine- and cystatin C-based estimates. American Journal of Kidney Diseases 201362 253-260. (doi:10.1053/j.ajkd.2013.03.013)

23 De Nicola L, Donfrancesco C, Minutolo R, Lo Noce C, Palmieri L, De Curtis A, Iacoviello L, Zoccali C, Gesualdo L, Conte G et al. Prevalence and cardiovascular risk profile of chronic kidney disease in Italy: results of the 2008-12 National Health Examination Survey. Nephrology, Dialysis, Transplantation 201530 806-814. (doi:10.1093/ ndt/gfu383)

Received 28 March 2015

Revised version received 30 June 2015

Accepted 20 July 2015 